\section{A New Procedure} for the Production of Red Gold Purples at the "Manufacture Nationale de Céramiques de Sèvres"

\section{Olivier Dargaud ${ }^{1,2}$, Lorenzo Stievano ${ }^{3^{*}}$ and Xavier Faurel ${ }^{2}$}

${ }^{1}$ Ecole Nationale Supérieure de Chimie de Paris, 11 rue Pierre et Marie Curie, 75005 Paris, France ${ }^{2}$ Laboratoire de la Manufacture Nationale de Sèvres, Place de la Manufacture, 92310 Sèvres, France ${ }^{3}$ Laboratoire de Réactivité de Surface, UMR 7609 CNRS, Université Pierre et Marie Curie, Case 178, 4 Place Jussieu, 75252 Paris Cedex 05, France

" To whom correspondence should be addressed. E-mail: Iorenzo.stievano@upmc.fr

Tel. +33-144273623

\begin{abstract}
A new procedure for the production of red gold purples was developed at the "Manufacture de Sèvres" for the production of high-quality red gold enamels. A significant improvement in the synthesis of the red gold purple $n^{\circ} 601$ compared to the historical method used since the 18 th century was achieved by optimising, on physico-chemical bases, the conditions of synthesis of the starting gold colloid. In particular, the use of a purer tin precursor, a better control of the reaction times and of the $\mathrm{pH}$ conditions via the use of a hydrogenocarbonate buffer allowed a complete control of the tint of synthesised purple and of the resulting red enamel. This method allows the completely reproducible synthesis of consecutive batches of a constant red colorant, which ultimately permits a standardisation in the amount of gold added into other goldcontaining enamels (more than 8 other enamels). Compared to the other red enamels synthesised throughout his whole history, the new $\mathrm{n}^{\circ} 601$ can be classified among the most beautiful and valuable red
\end{abstract}

enamels ever produced at the "Manufacture de Sèvres".

\section{Introduction}

In the 13th century, during his long expedition in China, Marco Polo noticed a fine and translucent ceramic material so far unknown, and named it "porcellana" (porcelain) after a nacreous shell very fashionable in those times. However, it is only in the course of the 17th century that porcelains of appropriate quality could be produced in Europe. In 1740, an ingenious ceramist named Claude Imbert Cérin formulated a magnificent white paste in Chantilly, and was invited to establish a manufacture of porcelains in the workshops of the Château de Vincennes under the protection of Count Philibert Orry, General Inspector of Finances of Louis XV. In 1745 the manufacture was nationalised and put under the direct protection of the king, and in 1756 the now-called "Manufacture Royale" moved to the actual site of Sèvres [1,2].

Among the available colours at the "Manufacture Royale de Sèvres" in the middle of the 18th century there were already gold-based purples. The colour of gold purples arises from a strong light absorption of the gold particles in the green region of the visible spectrum caused by surface plasmon excitation and from the interband absorption of metallic gold in the blue [3]. The hue of the colour strongly depends on the size and shape of the gold particles [4-6], and may change from bright red to violet. This wide range of possible colours allows the utilisation of gold purples in the composition of several different enamels. For instance, gold stains can be mixed with "Bleu de Sèvres", giving dark blueviolets or special glazing films for the production of the famous "rose Pompadour". The production method, which has been inherited for two hundred years, can be divided into two steps. First a colloidal sol of gold is synthesised. Then this sol is added to a powdered flux, dried and ground to fine powder. Once suspended in turpentine, the enamel is then used by the artists in the decoration of porcelains and afterwards fired at variable temperatures up to $880^{\circ} \mathrm{C}$.

Based upon notes dating back to 1744, Vincennes' goldbased enamels were bought from Pierre Antoine Henri Taunay [7]. Until now, the colloid has been traditionally produced thanks to a method developed at Sèvres [8] based on the one used for making Purple of Cassius, a mixed colloid of tin(IV) hydroxide and metallic gold, obtained by the reaction of tin(II) chloride and tetrachloroauric acid $[9,10]$.

Purple of Cassius is a relatively "recent" alternative to gold ruby glass, a silicate glass containing nanometre sized metallic gold metal particles imparting to the glass its distinctive red colour, the preparation of which has been known since Roman times [11]. Ruby glass is usually made by adding several hundred ppm of a gold precursor to the melt of a silicate glass. At the usual melting temperatures around $1400^{\circ} \mathrm{C}$ the 
gold dissolves in the melt and remains in this state on quenching to ambient temperature. Only when the quenched glass is annealed at about $500^{\circ} \mathrm{C}$ for times of the order of minutes or hours does it strike red owing to the formation of metallic gold nanoparticles. By using purple of Cassius, on the contrary, the long firing processes to make the reduction and germination of gold particles [12-16] can be skipped, since purple of Cassius already contains gold particles of the right size.

The first to discover the synthesis of gold purple was probably Rudolf Glauber in the 17th century [9], but the paternity is commonly accorded to Andreas Cassius of Lyden, whose son wrote down the well-known recipe in 1685, giving his name to the gold purple produced using tin [10]. In his synthesis, tin metal powder was directly added to a tetrachloroauric acid solution. Conversely, the recipe developed at Sèvres makes use of stannous chloride obtained by the oxidation of tin metal with hydrochloric acid and a few drops of nitric acid [8]. This method does not lead to pure tin dichloride, the oxidation of tin metal giving rise to a mixture of tetravalent and divalent tin compounds, and therefore a large amount of tin, up to 50 grams, is needed for the complete reduction of 5 grams of gold. In a variant of this method, the so-called Bolley method [8,17], stannous chloride is prepared by action of tin on ammonium hexachlorostannate. However, both methods remain quite rudimentary from a chemical point of view, and do not allow the accurate reproduction of a well-defined colour, often giving rise to conspicuous variations in the hue. Moreover, in both methods, the tin precursor is not a well-defined compound and is used in large excess. The final purples therefore contain an excessively elevated amount of tin. The problem of the production of a reproducible purple has been considered several times in the course of the 19th century, and various improvements of the traditional method were proposed [17, 18].

Among the several batches of gold enamel synthesised in

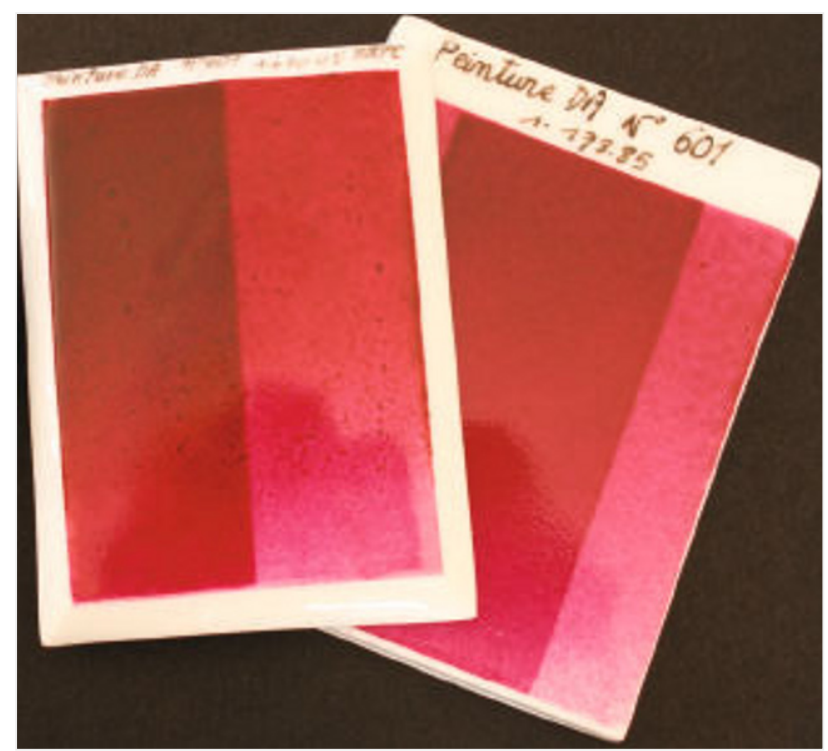

the course of the last centuries, a particularly valuable purple was produced in 1985 (Fig. 1). To take full advantage of the brilliance of this colour, a new flux formula was developed, giving birth to Sèvres $n^{\circ} 601$ red gold purple. This colour is characterised by a particularly bright and clear tint, and can be fired up to $880^{\circ} \mathrm{C}$ without turning brown. The drawback of this new formula, however, is that the quality of the enamel is extremely sensitive to the red hue of the colloid used.

In the framework of a more general study of the improvement of the quality of enamels at Sèvres, this paper reports on the optimisation of the synthesis of the red gold purple $n^{\circ} 601$. The first part of this work is mainly centred on the definition, on physico-chemical basis, of the best conditions of the colloid synthesis, which is the most delicate step in the preparation of this enamel, and on the influence of these conditions on the hue of the purple. In the second part, the scaling up of this process on going from small bench assays to reproducible large production-size amounts of this precious enamel is reported.

\section{Experimental}

\section{Materials}

Synthesis of the gold colloid:

A mother solution of tetrachloroauric acid is prepared by dissolving $1.25 \mathrm{~g}$ of gold metal in hot aqua regia (1 part of nitric acid to 2 of hydrochloric acid). The solution is then concentrated in a Rotavapor until it becomes deeply red, and slowly cooled to ambient temperature. The light yellow, needle-shaped crystals that precipitate upon cooling are dissolved then in $500 \mathrm{ml}$ of distilled water.

A mother solution of tin chloride is also prepared by dissolving 1.5 grams of $\mathrm{SnCl}_{2}$ anhydrous (Merk) in $200 \mathrm{ml}$ of distilled water previously acidified with a few drops of hydrochloric acid.

For each test, $20 \mathrm{ml}$ of the tetrachloroauric acid mother solution are diluted to $100 \mathrm{ml}$ with distilled water. The $\mathrm{pH}$ of the solution could be left free, according to the traditional method, or acidified with an excess of hydrochloric acid, or buffered at $\mathrm{pH} 6.4$ by the addition of $\sim 0.8 \mathrm{~g}$ of sodium hydrogenocarbonate. The addition of larger quantities of $\mathrm{NaHCO}_{3}$ produced an increase of the $\mathrm{pH}$ up to about $\sim 8.10$ $\mathrm{ml}$ of the tin chloride solution are then added dropwise at a constant rate under vigorous stirring. The rate of addition of the $\mathrm{SnCl}_{2}$ is customised to perform the total addition in the desired time (from a few seconds to one hour). After addition, $200 \mathrm{ml}$ of normal hot water are poured into the reaction solution and after a few minutes the colloid flocculates. A dark and intensely coloured purple precipitate, completely gathered at the bottom of the reaction vessel in one hour, is obtained. The precipitate is then recovered and washed four times with distilled water.

Figure 1

Red enamels produced at the "Manufacture de Sèvres" 
Synthesis of the flux

A special flux was prepared by mixing and grinding together appropriate quantities of minium, sodium carbonate, kaolin, quartz, boric acid and silver nitrate. The ground powder was melted in a Meker furnace at $1200^{\circ} \mathrm{C}$ for 30 minutes, and rapidly quenched in water. Clear and translucent, the flux was ground to a fine powder in a jar with smooth stones and sieved at 180 mesh before use. The final composition (in wt. \%) of the flux is: $\mathrm{PbO}$ 36.5; $\mathrm{Na}_{2} \mathrm{O}$ 4.0; $\mathrm{Al}_{2} \mathrm{O}_{3}$ 9.0; $\mathrm{SiO}_{2}$ 36.5; $\mathrm{B}_{2} \mathrm{O}_{3}$ 14.0. The silver content is $\sim 2$ wt. \%.

\section{Synthesis of the purple enamel}

The volume of the aqueous purple suspension is reduced by evaporation without drying, added to the dry flux and ground together to reach an average particle size of $2.5 \mu \mathrm{m}$ (checked by a laser granulometer). The final metallic gold content must be $\sim 1 \%$ of the total mass. Samples of finished enamelled porcelain were prepared by painting a flat piece of porcelain with the synthesised purples by using a common brushtapping technique called "putoisage". The samples were then fired in a muffle oven at $880^{\circ} \mathrm{C}$, i.e., the usual temperature used for Sèvres enamels.

\section{Physico-chemical characterisation}

X-ray powder diffraction (XRD) patterns were collected on a Siemens D 500 X-ray diffractometer (Cu Ka, wavelength = $1.5406 \AA$ ). The scanning range was set between $5^{\circ}$ and $80^{\circ}$ $(2 \theta)$ with a step size of $0.02^{\circ}$. The profile of the 111 reflection of gold was used to calculate the volume averaged particle diameter (coherence length) using the program Topas (Bruker) employing the Scherrer method. The instrumental broadening was taken into account by calibration with an $\alpha$ quartz reference standard.

The UV-vis-NIR spectra were recorded on a Cary 5E UV-visNIR spectrometer, which permits measurements on solid samples by a diffuse-reflectance light path. The samples were installed into the sample cell (a $5 \mathrm{~cm}$ diameter disk) and their surface smoothened. The measurements were carried out in air at room temperature. The baseline was set by using a Teflon standard.

The morphologic characterisation of the gold metal particles was performed in a JEOL 100 CXII Transmission Electron Microscope (TEM) operating at $100 \mathrm{kV}$. In order to obtain suitable samples, the powdered enamels were dispersed in ethanol by ultrasonication. A drop of the suspension was then deposited onto a thin holey-carbon film supported on a copper microscopy grid (200 mesh, 3.05 $\mathrm{mm}$ ) and left to dry. The analysis of the size and distribution of the gold particles has been performed by TEM imaging. Histograms of particle size distributions are shown in Fig. 4.

In order to investigate by TEM the enamel prepared at $\mathrm{pH}$ 6.4 , the enamelled face of a flat piece of porcelain fired at $880^{\circ} \mathrm{C}$ was fixed on a microscopy slide with Canada balsam. The ceramic part was removed with a stonecutter, until only the red enamel layer was left. This part was carefully removed and softly ground to fine powder.

\section{Results and discussion}

\section{Synthesis of the gold colloid}

The addition of the tin(II) chloride to the tetrachloroauric acid solution provokes the reduction of the gold, and thus the seeding and growth of gold metal particles, according to the following reaction [10]:

$$
3 \mathrm{Sn}^{2+}+2 \mathrm{AuCl}_{4}^{-} \rightarrow 3 \mathrm{Sn}^{4+}+2 \mathrm{Au}+8 \mathrm{Cl}^{-}
$$

It is worth noting that the role played by tin chloride is not restricted to the reduction of gold. In fact, the gold particles co-precipitate together with stannic acid, which is formed during the reaction after the oxidation of divalent tin, and are kept apart by being enclosed in its colloidal matrix [10]. Therefore, the knowledge of the nature of the tin species present during the reaction is fundamental to optimise the synthesis of the purple. As a first step, it was thus decided to exchange the ill-defined tin precursor traditionally used in the synthesis at Sèvres for commercial anhydrous tin(II) dichloride.

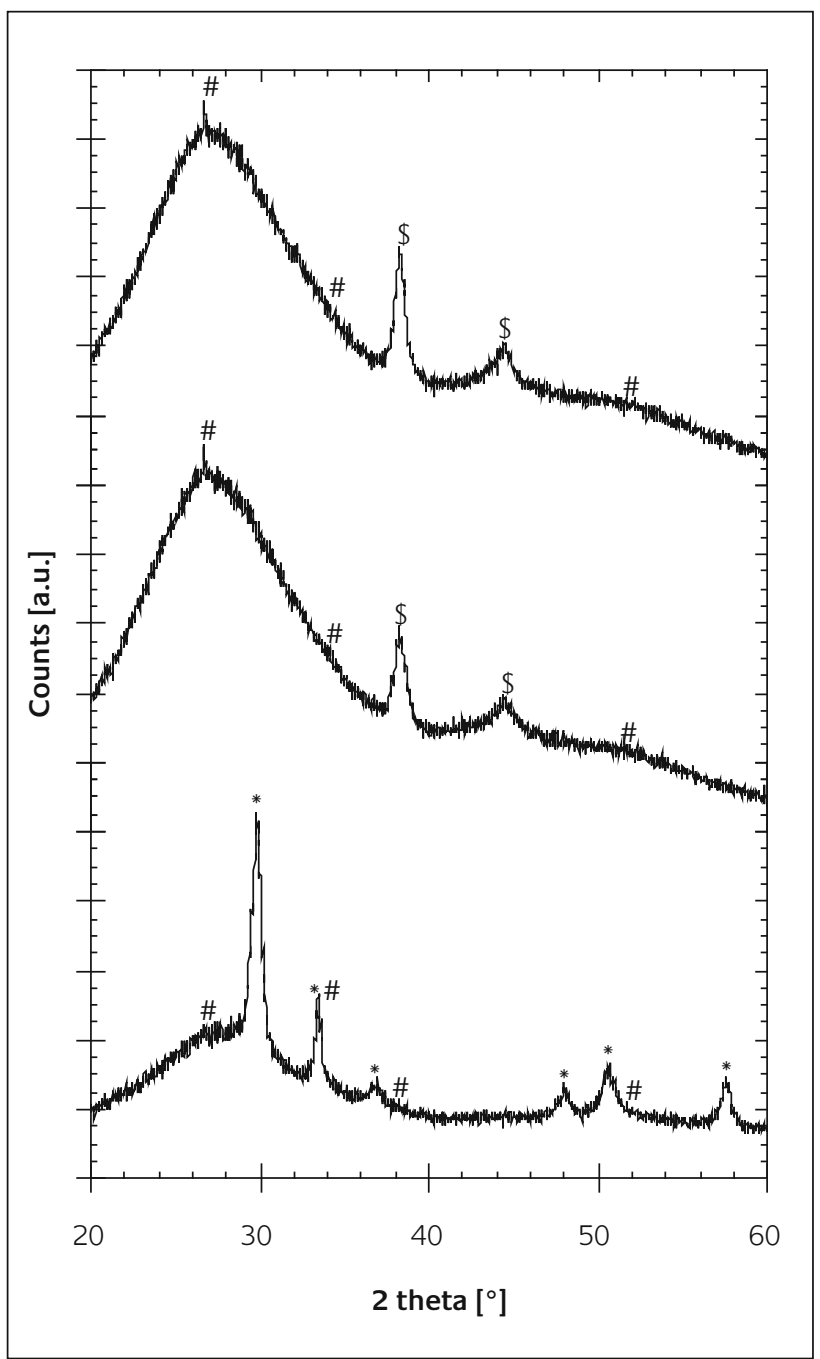

\section{Figure 2}

$X R D$ diffraction patterns of the dried gold sols prepared with addition times of $30 \mathrm{~s}$ at $\mathrm{pH} 1$ (top), $\mathrm{pH} 6.4$ (middle) and $\mathrm{pH} 8$ (bottom) after mixing with the powdered flux. Legend: \$ Gold; \# Cassiterite $\left(\mathrm{SnO}_{2}\right)$; * Romarchite (SnO) 


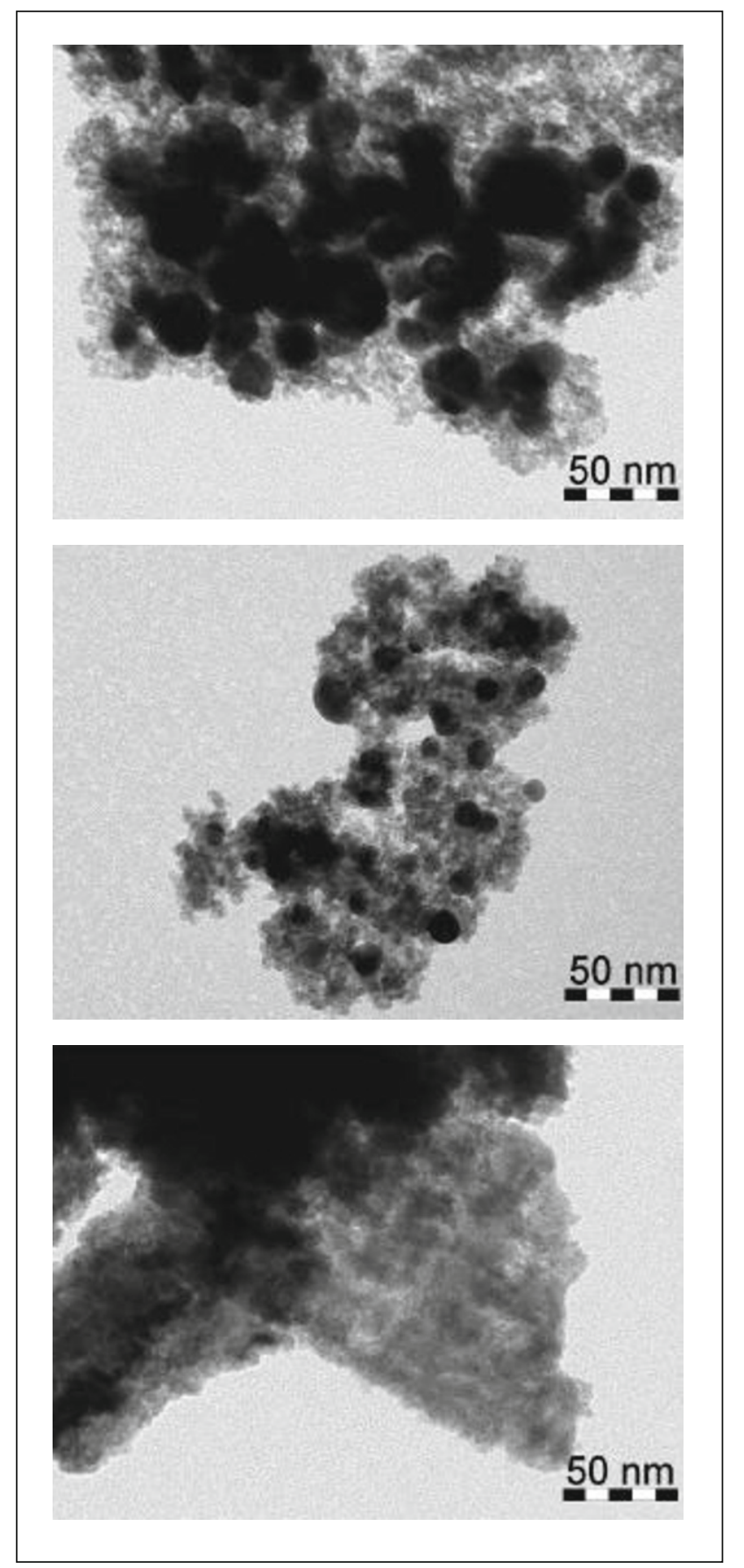

\section{Figure 3}

Samples prepared with addition times of $30 \mathrm{~s}$ at pH 1 (top), pH 6.4 (middle) and pH 8 (bottom) examined by TEM. Black gold particles are visible on the surface of colloidal stannic acid at pH 1 and 6.4

This choice permitted a better control of the state of tin in solution and allowed, as a consequence, a decrease by nearly a factor of ten of the total amount of tin used in the synthesis.

Another critical point in the synthesis of a gold colloid is expected to be the addition rate of the $\mathrm{SnCl}_{2}$ solution. Indeed, short times are known to give rise to red samples and long times to produce violet purples instead [7]. Moreover, the colour of the obtained sol seems to be also strongly dependent on the $\mathrm{pH}$. The influence of these two variables was thus studied by varying the total addition time from a few seconds to one hour and the $\mathrm{pH}$ from acidic ( $\mathrm{pH} 1)$ to basic ( $\mathrm{pH} 8)$.

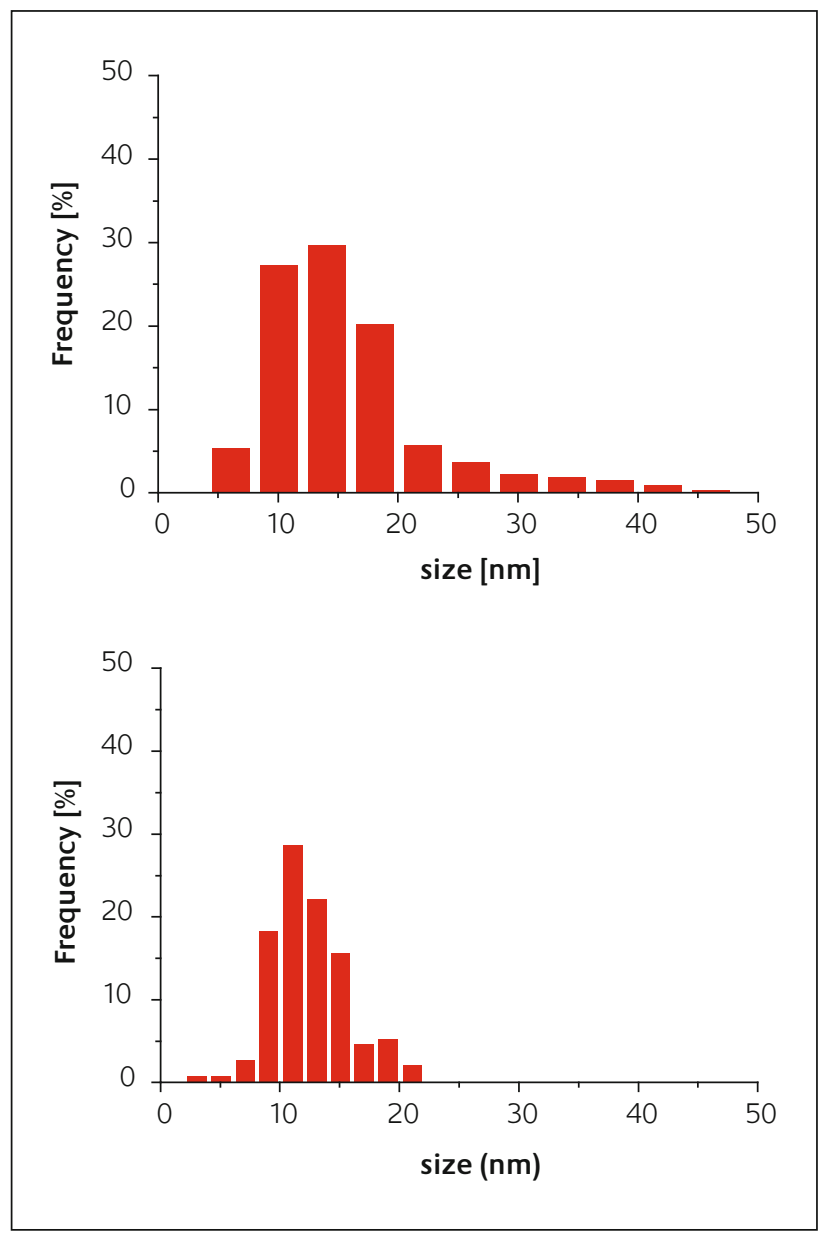

\section{Figure 4}

Particle size distribution histograms obtained from TEM imaging for samples prepared with addition times of $30 \mathrm{~s}$ at $\mathrm{pH} 1$ (top) and $\mathrm{pH}$ 6.4 (bottom)

At acidic $\mathrm{pH}$, either without $\mathrm{pH}$ control (historical methods) or at $\mathrm{pH} 1$ (excess of hydrochloric acid), an addition time of 30 seconds gives fuchsia-coloured solutions. After recovering the flocculate and mixing it with the flux, XRD diffraction (Fig. 2) indicates the presence of gold particles with an average size of about $12 \mathrm{~nm}$, and of cassiterite, $\mathrm{SnO}_{2}$. The analysis of TEM micrographs (Fig. 3) gives an average size of $16 \mathrm{~nm}$, but also show that there is a very large size distribution, ranging from 4 to $52 \mathrm{~nm}$ (Fig. 4). Once fired, these samples give too dark and too blue enamels. When the addition time of the $\mathrm{SnCl}_{2}$ is increased from 5 minutes to several hours, a violet purple is obtained. This sample is still too violet after firing.

In basic solutions ( $\mathrm{pH} 8)$, a dark blue precipitate is readily obtained. The precipitate becomes dark yellow-green after drying and grinding. XRD (Fig. 2) and electron diffraction performed in the electron microscope indicates the precipitation of mainly romarchite $(\mathrm{SnO}$, containing divalent tin), together with some cassiterite, whereas no metallic gold is present. Electron microscopy also shows the presence of dark precipitates (Fig. 3), in line with the precipitation of amorphous gold oxide, as expected at basic $\mathrm{pH}$. During the firing process, gold is reduced and a sallow fuchsia-violet enamel is obtained. 
If the $\mathrm{pH}$ is buffered at 6.4 with sodium hydrogenocarbonate, a bright red precipitate is produced if the addition time of $\mathrm{SnCl}_{2}$ is kept below $1 \mathrm{~min}$. The colour of this sample is very similar to that of the $n^{\circ} 601$ reference colour. The XRD pattern of a sample prepared using an addition time of $30 \mathrm{~s}$ shows the presence of gold particles with an average size of $10 \mathrm{~nm}$, not very different from the one obtained at acidic $\mathrm{pH}$. However, electron microscopy shows that the size distribution of the gold particles is much narrower than for samples obtained at acidic pH, going from 3 to $20 \mathrm{~nm}$ (Fig. 4). The firing of this sample produced red purples virtually identical to the original $n^{\circ} 601$ enamel obtained in 1985. If an addition time longer than $1 \mathrm{~min}$ is allowed for, the hue tends more toward fuchsia, even if the tint is less violet than in the case of acidic $\mathrm{pH}$.

It is interesting to notice that, while the reduction of the gold precursor to gold metal is assured by the oxidation of divalent tin, the use of a bicarbonate buffer allow a very strict control of the particle size. In this case, the bicarbonate ions might have a role in the stabilisation of the gold nanoparticles similar to that of citrate, commonly employed in the synthesis of gold colloids [19]. In fact, in citratestabilised gold colloids, citrate anions are known to remain strongly adsorbed on the surface of the gold particles, rendering them negatively charged. As a consequence, repulsion between charged particles stabilises the colloidal suspension preventing the particles from further aggregation [19]. Even though the citrate method is widely used in the preparation of gold colloids, the use of bicarbonate is, to our knowledge, totally original and its possible role in the stabilisation of gold nanoparticles deserves further investigation.

\section{Effect of the synthesis conditions on the hue of the purple}

In order to measure the influence of the distributions of particles size on the hue of the synthesised purples and subsequently on the fired enamels, the samples prepared with addition times of 30 seconds at different $\mathrm{pH}$ values were investigated by UV-Vis spectroscopy. In fact, as already stated in the introduction, the surface plasmon excitation energy of the gold particles, and thus the hue of the purple, is strongly dependent upon the size of the particles [4-6]. In the present case, more or less broad distributions of particle sizes are found in the different samples, leading to the simultaneous presence of different adsorption wavelengths and thus producing broad adsorption envelopes.

The UV-Vis spectra of the gold sols after mixing with the flux, together with the spectrum of the flux alone, are shown in Fig. 5. The absorption peaks appearing at 425, 590 and $620 \mathrm{~nm}$ are typical of the flux, the first one probably due to the surface plasmon resonance of silver metal particles

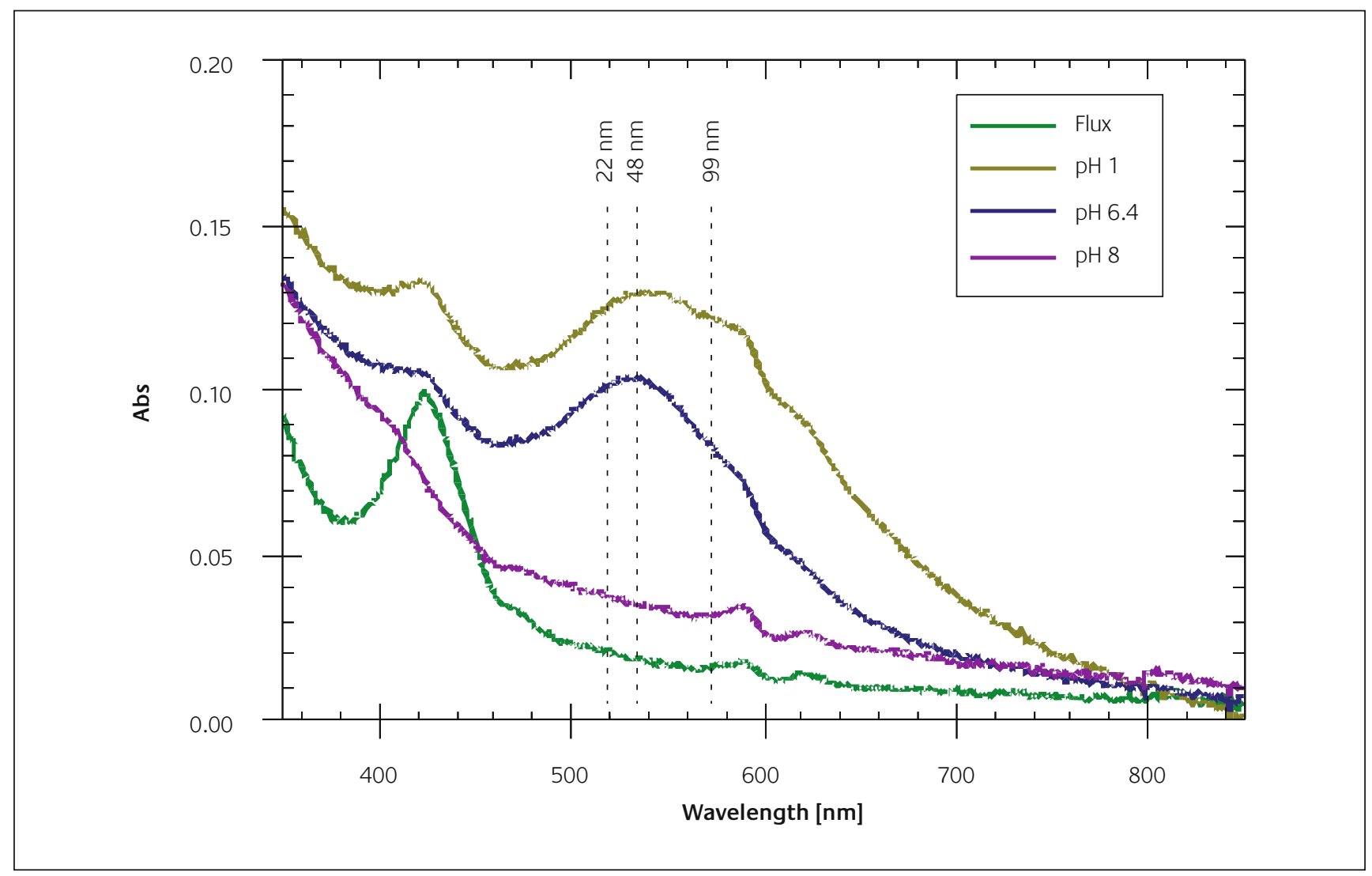

\section{Figure 5}

UV-vis spectra of the purple samples prepared with addition times of $30 \mathrm{~s}$ at pH 1 (top), pH 6.4 (middle) and pH 8 purples after mixing with the flux. The spectrum of pure flux is also shown as a reference. The vertical lines correspond to the position of the maxima of the plasmon resonance absorption for monodispersed gold particles of the indicated size (from ref. [20]) 


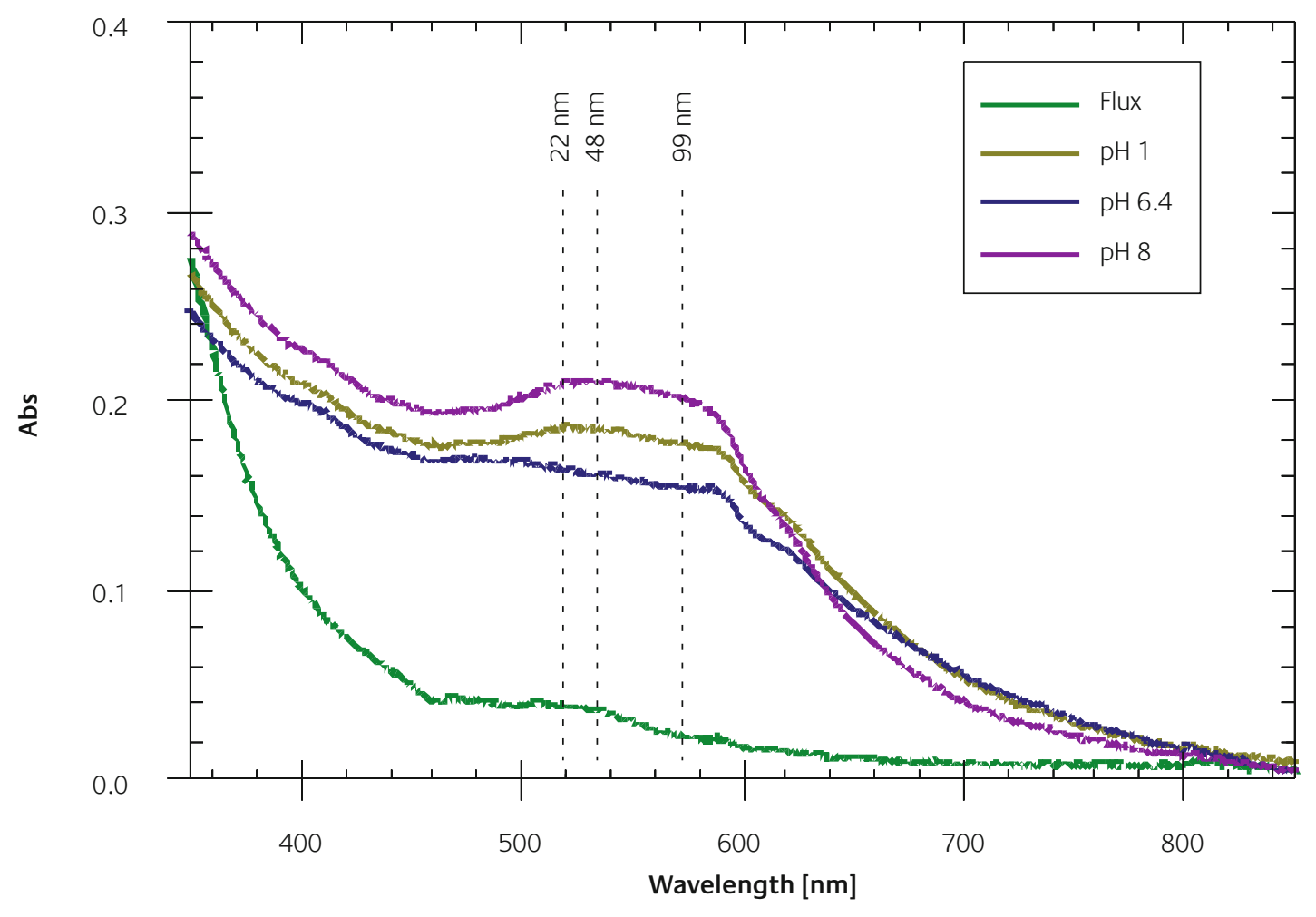

\section{Figure 6}

UV-vis spectra of flat pieces of porcelains enamelled with purples prepared with addition times of $30 \mathrm{~s}$ at pH 1 (top), pH 6.4 (middle) and pH 8 and fired at $840^{\circ} \mathrm{C}$. The spectrum of a piece of porcelain enamelled with pure flux is also shown as a reference. The vertical lines correspond to the position of the maxima of the plasmon resonance absorption for monodispersed gold particles of the indicated size (from ref. [20])

produced during the firing of the flux at $1200^{\circ} \mathrm{C}$. This band decreases in intensity but is still visible in the purple samples. The plasmon resonance of the gold metal particles, absent in the sample prepared at $\mathrm{pH} 8$ in agreement with the absence of metallic gold in this sample, is very intense in the two samples prepared at $\mathrm{pH} 1$ and $\mathrm{pH}$ 6.4. The maximum of this band is positioned at $520 \mathrm{~nm}$ in the case of the sample prepared at $\mathrm{pH}$ 6.4, whereas it is shifted to about $540 \mathrm{~nm}$ in the sample prepared under acidic conditions. If the position of these bands is compared with that found for model monodisperse gold particles stabilised in aqueous solution [20], one finds that the maximum for the sample prepared at $\mathrm{pH} 1$ corresponds to particles of about $50-60 \mathrm{~nm}$, whereas a size of about $40 \mathrm{~nm}$ can be deduced for the sample prepared at $\mathrm{pH}$ 6.4. If one compares these results with the average particle sizes found by TEM and XRD, one can see that large particles seem to contribute more to the colour than the small ones. Finally, it is worth noting that the bandwidth measured for the sample prepared at acidic $\mathrm{pH}$ is much larger than the one of the sample prepared with the hydrogenocarbonate buffer, showing a broad tail at high wavelengths which extends to the yellow and red part of the visible spectrum, thus influencing the final hue of this purple.

A similar picture can be drawn for the samples obtained after painting and firing the enamels at $880^{\circ} \mathrm{C}$ (Fig. 6). In this case, the maximum obtained for the sample prepared at $\mathrm{pH}$
6.4 is clearly shifted to lower wavelengths compared to those of the samples prepared under acidic or basic conditions, in agreement with the observed strengthening of the red hue of this sample compared to the other ones, which are more violet.

It is worth noting that the plasmon absorption bands are significantly wider in the fired enamels than in the respective purples before firing. This observation probably indicates an increase in the particle size and shape distribution in all samples, probably due to the coalescence of smaller particles as suggested by the presence of oblong gold particles observed by TEM. This effect of coalescence changes with the mean diameter of flux particles, and the best colours are obtained with an average size of the flux particles of $2,5 \mu \mathrm{m}$. A small size, in fact, favours a high dispersion of the initial gold colloid and reduces the possibility of coalescence of the metal particles. This observation agrees with the traditional longer milling times usually employed for $n^{\circ} .601$ gold purple compared to other enamels of Sèvres's palette.

From bench assays to reproducible large batch yields Summarising, the main improvements to the method used at Sèvres for the preparation of gold red purple that were realised in the present work consist in:

1 The use of a hydrogenocarbonate buffer to fix the $\mathrm{pH}$ at 6.4 during the precipitation of the gold sol. 


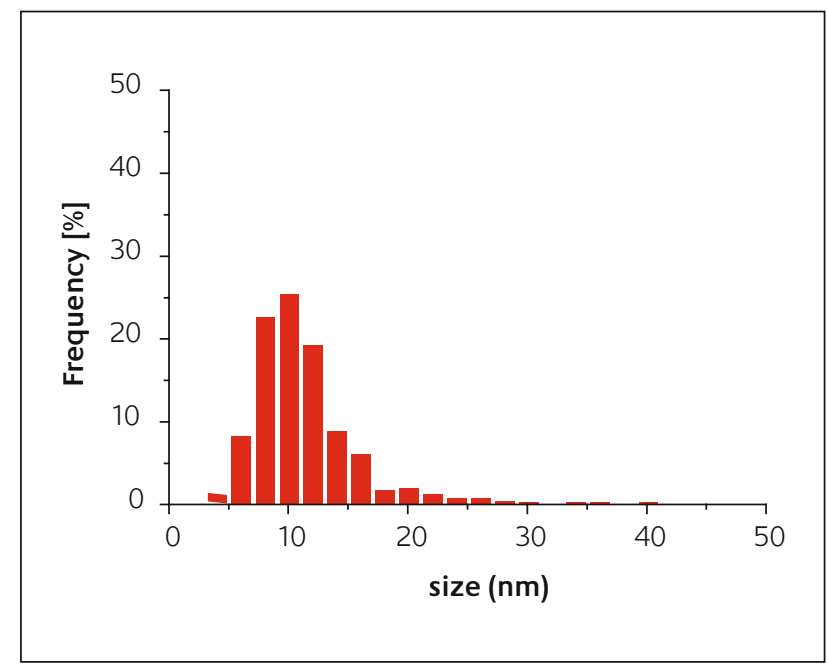

Figure 7

Particle size distribution histograms obtained from TEM imaging for the red enamel after painting and firing at $880^{\circ} \mathrm{C}$

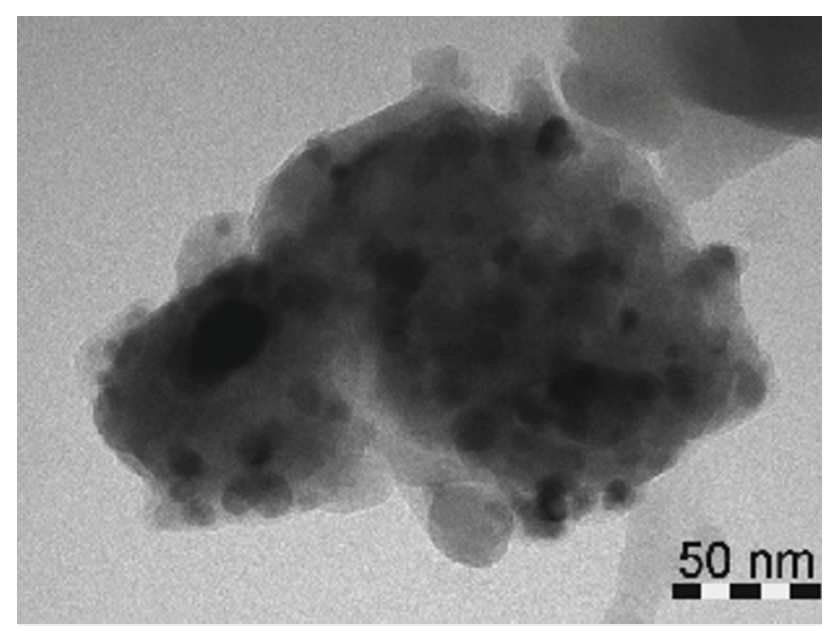

\section{Figure 8}

A fragment of the red enamel obtained by firing the purple prepared at pH 6.4 examined by TEM. Agglomerates of separate gold particles are visible enclosed in the lead glaze

2 The use of pure commercially available anhydrous tin chloride (II) instead of tin metal as the source of tin.

3 The use of only 1.5 equivalent of the tin dichloride solution, with total addition times shorter than a minute.

Only by setting these conditions was it possible to obtain good and highly reproducible red purples that could satisfy the set painters. These improvements were thus employed to scale up the synthesis to production scale.

More specifically, the first two conditions can be directly transferred from the bench assay to the production process. The only condition needing optimisation is in fact the addition rate, which was finally set by a trial-and-error method. The resulting final recipe obtained for the process is given in Panel 1.

This protocol was found to be highly reproducible and leads to the synthesis of red purples very similar in the final hue of fired colour. A batch of purple prepared using this recipe was checked by TEM, which showed the presence of gold particles with an average size of $11 \mathrm{~nm}$, with a size distribution going from 4 to $40 \mathrm{~nm}$ (Fig. 7).

The same sample was also studied after firing at $880^{\circ} \mathrm{C}$ (Fig. 8). As expected, in this sample several particles are often grouped together in the same grain of enamel. However, only very few large particles are formed by coalescence of smaller ones, and they can be easily distinguished due to their quite unusual oblong shape.

This new recipe is now employed at Sèvres for the production of red gold purple used in the decoration of Sèvres porcelains.

\section{Conclusions}

A significant improvement in the preparation of the red gold purple $n^{\circ} 601$ used at the "Manufacture Nationale de Céramiques de Sèvres" was achieved by optimising, on physico-chemical bases, the conditions of synthesis of the starting gold colloid. In particular, the use of a purer tin

\section{Panel 1}

The new recipe now employed at Sèvres for the production of red gold purple

i 52 grams of gold are dissolved in aqua regia. The recovered tetrachloroauric acid crystals are dissolved in $500 \mathrm{~mL}$ of distilled water. $38.5 \mathrm{~mL}$ of this solution (corresponding to $4 \mathrm{~g}$ of gold) are diluted to $20 \mathrm{~L}(0.375 \mathrm{~g} / \mathrm{L}$ of gold) in common water and heated to $35^{\circ} \mathrm{C}$;

ii At the same time, 5.87 grams (1.52 equivalents) of anhydrous stannous chloride are dissolved in $200 \mathrm{~mL}$ of distilled water acidified to $\mathrm{pH} 1$ by HCl;

iii The gold solution (containing 4 grams of gold) is acidified to $\mathrm{pH} 1$ by adding $200 \mathrm{~mL}$ of hydrochloric acid under vigorous stirring, and buffered at $\mathrm{pH} 6.4$ by slowly adding sodium hydrogenocarbonate;

iv The tin solution is added dropwise to the gold solution for a total time of 55 seconds;

$\checkmark$ The colloid flocculates after a few minutes and slowly precipitates. The sol is washed four times and the volume is reduced first by slowly removing the supernatant and subsequently by natural evaporation;

vi The concentrated aqueous purple is added to the powdered flux and ground until an average particle size of $2.5 \mu \mathrm{m}$ is reached. Final adjustments of the grain size are obtained by grinding the powder with absolute ethanol. 
precursor, a better control of the $\mathrm{pH}$ conditions and of the reaction times allowed a complete control of the tint of synthesised purple. This method allows the completely reproducible synthesis of consecutive batches of a constant red colorant, more red and deeper than any other red purple produced at Sèvres in the last 30 years, and ultimately permits a standardisation in the amount of gold added into other gold-containing enamels (more than 8 other enamels).

\section{Acknowledgements}

The authors wish to thank the whole staff of the Manufacture for their help. In particular, C. Bouttaz is thanked for her active participation in the production of the painted samples and in defining the best conditions of flux milling. F. Bequet is thanked for his valuable help in the discussions, in the melting of the fluxes and in the production process, allowing the "Manufacture Nationale de Sèvres" to get its reservoir pots finally filled with large quantities of this precious enamel.

F. Warmont (LRS) is gratefully acknowledged for her precious help in TEM analysis. J.-F. Lambert (LRS) and F. E. Wagner (Technische Universität München, Garching, Germany) are gratefully acknowledged too for their critical review of this manuscript, providing us with nice feedback and invaluable insights.

\section{About the authors}

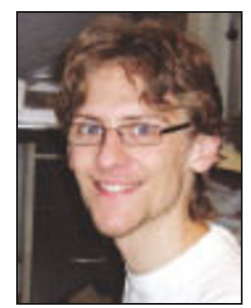

Olivier Dargaud graduated in chemistry at the "Université Pierre et Marie Curie" in Paris (France) and has just obtained a Master degree at the "Ecole Nationale Supérieure de Chimie de Paris". He is now beginning a PhD in chemistry studying nucleation phenomena in glasses at the "Université Pierre et Marie Curie" in collaboration with "St-Gobain Recherches"

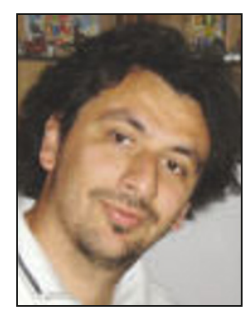

Lorenzo Stievano studied industrial chemistry at the "Università Ca' Foscari” in Venice (Italy), where he obtained a $\mathrm{PhD}$ in Chemical Sciences in 1999. Since 2001, he is associate professor of inorganic and materials chemistry at the "Université Pierre et Marie Curie" in Paris (France). His main research activities are centred on the study of the structure and of the surface reactivity of inorganic materials.

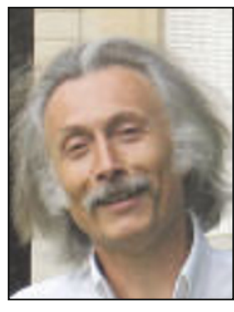

Xavier Faurel obtained his degree in chemical engineering of ceramics and glasses at the "Conservatoire National des Arts et Métiers" of Paris in 1980. Since then he has been responsible for the R\&D laboratory of the "Manufacture Nationale de Céramiques de Sèvres" (France). He is in charge of developing and promoting the scientific and technological investigation in the domain of ceramic materials at the Manufacture.

\section{References}

1 G. Lechevallier-Chevignard, La Manufacture de Porcelaine de Sèvres. Renouard - H. Laurens, Paris (1908)

2 M. Brunet and T. Préaud, Sèvres - Des Origines a nos Jours. Office du Livre, Fribourg (1978)

3 C. Burda, X. Chen, R. Narayanan, and M.A. El-Sayed, Chem. Rev. 2005, 105, 1025-1102

4 P. Mulvaney, Langmuir 1996, 12, 788-800

5 U. Kreibig, J. Physique, Colloque C2 1977, 38, 97-103

6 S. Link, and M.A. El -Sayed, J. Phys. Chem. B 1999, 103, 4212-4217

7 A. d'Albis, Les Débuts des pourpres en France de Chantilly à Vincennes: Salomon Taunay et son fils Pierre Henry Taunay. Rev. Soc. Amis du Musée Nat. de Céram. 1994, 3, 34-39

8 A. d’Albis, Traité de la porcelaine de Sèvres. Edition Faton, Paris (2003) p. 224

9 L.B. Hunt, Gold Bull. 1976, 9, 134-139

10 J. Carbert, Gold Bull. 1980, 13, 144-149

11 D.J. Barber, and I.C. Freestone, Archaeometry 1990, 32, 33-44

12 S.D. Stookey, J. Am. Ceram. Soc. 1949, 32, 246-249

13 P. Rao and R.H. Doremus, J. Non-Crystalline Solids 1996, 203, 202-205

14 R.H. Doremus, J. Chem. Phys. 1964, 40, 2389-2396

15 R.H. Doremus, Proc. Symposium on Nucleation and Crystallization in Glasses and Melts, The American Ceramic Society, Colombus, OH, (1962) pp. 119-123

16 F. E. Wagner, S. Haslbeck, L. Stievano, S. Calogero, Q.A. Pankhurst, and K.P. Martinek, Nature 2000, 407, 691-692

17 A. Brongniart, Traité des arts céramiques ou des poteries considérées dans leur histoire, leur pratique et leur théorie, vol. 2, Fain et Thunot, Paris (1844) pp. 535-538

18 J. Lefort, Chimie des Couleurs, Victor Masson, Paris (1855) pp. 190-194

19 J. Turkevich, Gold Bull. 1985, 18 86-91

20 S. Link, and M.A. El-Sayed, Int. Rev. Phys. Chem. 2000, 19, 409-453 